\title{
Levels and Prevalence of Mental Health Functioning in Canadian University Student-Athletes
}

Krista J. Van Slingerland and Natalie Durand-Bush

University of Ottawa

Scott Rathwell

University of Lethbridge

\begin{abstract}
We examined the level and prevalence of mental health functioning (MHF) in intercollegiate student-athletes from 30 Canadian universities, and the impact of time of year, gender, alcohol use, living situation, year of study, and type of sport on MHF. An online survey completed in November $2015(N=388)$ and March $2016(n=110)$ revealed that overall, MHF levels were moderate to high, and more student-athletes were flourishing than languishing. MHF levels did not significantly differ across time based on gender, alcohol use, living situation, year of study, and type of sport. Eighteen percent reported a previous mental illness diagnosis and yet maintained moderate MHF across time. These findings support Keyes' (2002) dual-continua model, suggesting that the presence of mental illness does not automatically imply low levels of wellbeing and languishing. Nonetheless, those without a previous diagnosis were 3.18 times more likely to be flourishing at Time 1 (November 2015).
\end{abstract}

\section{Résumé}

Nous avons étudié la santé mentale d'étudiants athlètes provenant de 30 universités canadiennes, ainsi que l'influence des variables suivantes : temps de l'année, sexe, consommation d'alcool, condition de logement, année d'étude, et type de sport. Un questionnaire en ligne complété aux mois de novembre $2015(N=388)$ et mars $2016(n=110)$ a révélé que la santé mentale 
des participants variait d'un niveau moyen à élevé et n'était pas influencée par les autres variables. Un plus grand nombre de participants s'épanouissaient comparativement à ceux qui languissaient. Les participants rapportant un diagnostic de trouble mental (18\%) maintenaient tout de même un niveau modéré de santé mentale à travers le temps, suggérant que la présence d'une maladie mentale n'implique pas nécessairement un niveau de bien-être inférieur (Keyes, 2002). Toutefois, les étudiants athlètes sans diagnostic antérieur étaient plus aptes (3.18 fois) à s'épanouir au temps 1 de l'étude (novembre 2015).

Being a university student-athlete comes with complex pressures, in addition to those of normal student life, that can impact well-being and performance (Humphrey, Bowden, \& Yow, 2013; Neal et al., 2013). For example, student-athletes must manage both sport and academic demands and excel in both domains to maintain their athletic eligibility status. It is thus not surprising that student-athletes are predisposed to the same or an even greater risk of experiencing declines in their mental health and well-being as their non-athlete peers (Brewer \& Petrie, 2002; Neal et al., 2013). However, concern for the well-being of student-athletes has traditionally been restricted to their physical health and its influence on performance outcomes in sport and academia (Beauchemin, 2014). One potential explanation for this is the assumption that athletes are inherently mentally healthy (Bär \& Markser, 2013). Another is that mental health challenges and illnesses have not been openly discussed within this population due to prevailing stigma. Despite calls to address the health of student-athletes from a more holistic perspective (e.g., Watson \& Kissinger, 2007), the mental health and well-being of Canadian university studentathletes is relatively unstudied.

As such, this study was a first step in empirically examining mental health functioning (MHF) in a unique subpopulation of Canadian university students. We explored the levels and prevalence of MHF in a sample of USports (formerly Canadian Interuniversity Sport) student-athletes and determined whether time of year and individual differences (i.e., gender, alcohol use, living situation, year of study, type of sport) affected studentathletes' MHF.

\section{Mental Health and Illness}

Keyes (2002) refuted the notion that mental health and illness are mutually exclusive, and instead proposed a dual-continua model that features mental health and mental illness as related but distinct phenomena contributing to overall human functioning. According to Keyes (2002), mental health is a "syndrome of symptoms of positive feelings and positive functioning in life" (p. 604) that can be operationalized as the sum of the following core components of subjective well-being: emotional well-being (EWB), psychological well-being (PWB), and social well-being (SWB; Westerhof \& Keyes, 2010). Conversely, Keyes (2003) defined mental illness as "persistent and substantial deviation from normal functioning that impairs an individual's ability to execute [his/her] social roles, and generates emotional suffering" (p. 293). Within the category of mental illness reside conditions such as anxiety disorders, major depressive episodes, and unipolar and bipolar depression (Keyes, 2007). From this more comprehensive perspective of mental health, 
the presence of mental health in life is described as flourishing, while the absence of mental health is characterized as languishing (Keyes, 2005); these categorizations stand irrespective of both a mental illness diagnosis and subclinical symptoms of mental illness.

Studies with youth and college students (Renshaw \& Cohen, 2014; Suldo \& Shaffer, 2008) investigating subjective well-being and psychopathology or impaired functioning have shown support for Keyes's (2002) dual-factor model. Little research, however, has examined the coexistence of languishing, moderate mental health, and flourishing with mental illness, and no studies to our knowledge have measured MHF in a clinical population. That said, Peter, Roberts, and Dengate (2011) explored the relationship between Keyes' (2005) three categorizations of mental health (languishing, moderate mental health, and flourishing) and mental illness (depressive symptoms measured using the Center for Epidemiologic Studies Depression Scale [CES-D]) ${ }^{1}$ in Canadian university students $(N=1245)$. Of those who exhibited above-threshold depressive symptoms ( $n$ $=208$ ), $26.4 \%$ were languishing, $71 \%$ were moderately mentally healthy, and $2.4 \%$ were flourishing, demonstrating that it is possible to achieve moderate or high mental health with symptoms of mental illness. Similarly, Petrillo, Capone, Caso, and Keyes (2015) studied 1438 Italian adults aged 18-87 years by administering the Adult Mental Health Continuum-Short Form (MHC-SF) in conjunction with the CES-D. Their results showed that those with moderate mental health (53\%) also scored above the threshold for clinical depression $(M=18.85)$, and those who were flourishing $(28.4 \%)$ concomitantly experienced sub-threshold depressive symptoms $(M=13.24)$. Thus, despite experiencing symptoms of mental illness, these individuals exhibited moderate or high mental health. This suggests that it is valuable to gain insight into both mental health and mental illness indices to obtain a comprehensive view of overall functioning.

\section{Mental Health in University Students}

The mental health of university students has become a growing concern across Canadian university campuses. This population is at a great risk of experiencing mental illness, substance abuse, and suicide (Clapham, Jahchan, Medves, Tierney, \& Walker, 2012; Peter et al., 2011). Studies examining the mental health of Canadian university students conducted in the last decade have produced startling statistics. For example, undergraduate respondents from six Ontario post-secondary institutions indicated the most common factors affecting their academic performance were stress, difficulty sleeping, and anxiety. A high number of them reported being so overwhelmed by feelings of anxiety (47\%) and depression (30\%) in the last 12 months that they had difficulty functioning (American College Health Association [ACHA], 2009). Similarly, undergraduate and graduate respondents to a national survey reported that in the last year, they felt overwhelmed by all they had to do (89.1\%), felt very lonely (62\%), and had seriously considered suicide (8.6\%; ACHA, 2013).

Stress is shown to be an important antecedent to poor mental health in universityaged students, and occurs when the demands placed on individuals exceed their perceived resources and ability to cope (Mikolajczyk, Maxwell, Naydenova, Meier, \& Ansari, 2008). When excessive and perceived negatively, stress is psychologically distressing and can lead to negative emotional affect, depressive symptoms, and physical and mental illness (Mikolajczyk et al., 2008; Misra \& McKean, 2000; Verger et al., 2009). 
Antecedents of ill-being among university-aged populations. Psychological distress may vary significantly according to university students' gender, alcohol use, year of study, living situation, and status as a varsity athlete or non-athlete. For instance, the latest National College Health Assessment undertaken at 34 Canadian post-secondary institutions showed that a greater proportion of women perceived above average stress levels (60.2\%) compared to men (46.1\%; ACHA, 2013). Alcohol use is another factor that has been associated with not only ineffective emotional regulation, but also depressive symptoms and suicidal ideation in college and university students (e.g., Gratz, Conrad, \& Roemer, 2002). Given this association, it is alarming that about one-third (32\%) of undergraduates in a Canadian study reported hazardous drinking patterns (i.e., frequent binge drinking; Adlaf, Demers, \& Gilksman, 2005). Finally, year of study and living situation are identified risk factors for experiencing psychological distress, as the transition from high school to university can be particularly difficult (Verger et al., 2009)-especially for those students living off campus without parents or family (Adlaf et al., 2005). Multiple studies have documented high levels of stress, anxiety, and depression in first-year university students (e.g., Dyson \& Renk, 2006; Sasaki \& Yumasaki, 2007; Verger et al., 2009), and resulting declines in psychological and physical health (e.g., Pritchard, Wilson, \& Yamnitz, 2008), calling attention to this particularly difficult time in the development of young adults. Aside from gender, alcohol use, year of study, and living situation, competitive sport participation places additional demands on university students, which may lead to ill-being.

University student-athletes. Student-athletes are a distinctly identifiable subgroup of students on university campuses whose athletic participation offers unique benefits and challenges. On the one hand, sport participation can help student-athletes develop a positive identity, sociability, high self-esteem, self-discipline, and a sense of responsibility (Watt, Moore, \& Howard-Hamilton, 2001). On the other hand, playing an intercollegiate sport adds a complex layer to student life. Student-athletes face unique demands that can lead to distress, depressive symptoms, and low well-being (Humphrey et al., 2013; Kimball \& Freysinger, 2003; Miller \& Kerr, 2002; Yang et al., 2007). For instance, in addition to managing many of the same academic, emotional, and personal goals and concerns as their non-athlete colleagues, student-athletes must balance the often conflicting roles of student and athlete, manage an inflexible and demanding schedule, travel to competitions, monitor their nutrition and body composition, forge relationships outside of their sports network, and cope with physical fatigue and injury (Aries, McCarthy, Salovey, \& Banaji, 2004; Watt et al., 2001; Wilson \& Pritchard, 2005). These additional stressors can exacerbate an existing mental health condition or trigger a new psychological concern (Neal et al., 2013). Antecedents of ill-being in athletes are reportedly similar to those in the general population but also include overtraining, injury, competitive failure, aging, and retirement from sport (National Collegiate Athletic Association [NCAA], 2007). Of note, athletes who are female, freshmen, or experiencing pain are more likely to report symptoms of ill-being (Yang et al., 2007), and female athletes are also more likely to exhibit signs of physical and emotional exhaustion (Dubuc-Charbonneau, Durand-Bush, \& Forneris, 2014). Additionally, evidence suggests that type of sport may impact psychological and well-being outcomes. For example, patterns of athlete burnout may be sport-specific (Dubuc-Charbonneau et al., 2014) and individual-sport athletes may be more prone to experiencing depressive symptoms than team-sport athletes (Nixdorf, Frank, \& Beckmann, 2016). 
To summarize, the aforementioned studies suggest that mental health research and initiatives should become a priority across university campuses. While indices of mental health and illness have been explored with American and Canadian university student populations and NCAA student-athletes, the mental health of Canadian university student-athletes remains relatively unexplored. The purpose of this study was to provide foundational data on the mental health functioning (MHF) of USports student-athletes, to help steer the creation of mental health policies and important standards of practice in Canadian university sport. Uphill, Sly, and Swain (2016) suggest that Keyes' dual-continua model provides advantages in the assessment and enhancement of the mental health of athletes because it allows for the recognition and understanding of both axes of functioning, and because its verbiage may be less alienating and intimidating to athletes than that of traditional measures. With this in mind, and given the focus and value of Keyes' multidimensional functioning model in mental health research to date, it was used to guide the current study. The following research questions and hypotheses were examined:

1. What is the level and prevalence of MHF of student-athletes competing in Canadian USports at two different time points in their academic year (November 2015 = Time 1, March 2016 = Time 2)? Given that student-athletes are vulnerable to high levels of stress (Kimball \& Freysinger, 2003) and diminished levels of well-being (Neal et al., 2013; Watson \& Kissinger, 2007), it was hypothesized that student-athletes would exhibit moderate to low levels of MHF and there would be a lower prevalence of student-athletes flourishing compared to those languishing.

2. Are there significant differences in USports student-athletes' level of MHF between Time 1 and Time 2 based on gender, alcohol use, living situation, year of study, and type of sport? We hypothesized that studentathletes' MHF would significantly diminish from Time 1 (November 2015) to Time 2 (March 2016), given their prolonged experience of athletic and academic stressors (e.g. assignments, exams, playoffs) and vulnerability to compounding fatigue and burnout (Dubuc-Charbonneau et al., 2014). Furthermore, we expected that female student-athletes (Yang et al., 2007), and student-athletes who exhibited "hazardous drinking patterns" (Nelson \& Wechsler, 2001), lived off-campus without family (Adlaf et al., 2005), were enrolled in their first year of studies (Park, Edmondson, \& Lee, 2012), and participated in individual sports (Nixdorf et al., 2016) would display the lowest MHF in the sample.

\section{Methods}

\section{Participants}

Participants at Time 1 (November 2015) were 388 student-athletes (age range 18-26, $M_{\text {age }}=20$ years; $\left.S D=1.96\right)$ from 30 Canadian universities, competing in the USports system in the Canada West $(n=61)$, Ontario University Association $(n=118)$, Réseau du sport étudiant du Québec $(n=84)$, and Atlantic University Sport $(n=125)$ divisions. A total of 110 student-athletes from the initial sample of 388 volunteered to participate at Time 2 (March 2016). See Table 1 for a summary of sample characteristics. 
Student-Athlete Mental Health Functioning / K. J. Van Slingerland, N.Durand-Bush, S. Rathwell 154

Table 1. Summary of Sample Demographics

\begin{tabular}{|c|c|c|}
\hline Gender & Time $1(N=388)$ & Time $2(n=110)$ \\
\hline Male & $37.6 \%(n=146)$ & $25.5 \%(n=28)$ \\
\hline Female & $62.4 \%(n=242)$ & $74.5 \%(n=82)$ \\
\hline \multicolumn{3}{|l|}{ Alcohol use $^{\mathrm{a}}$} \\
\hline Non-drinker & $7.7 \%(n=30)$ & $12.7 \%(n=14)$ \\
\hline Non-binger & $53.1 \%(n=206)$ & $64.5 \%(n=71)$ \\
\hline Infrequent binger & $24.5 \%(n=95)$ & $20.6 \%(n=22)$ \\
\hline Frequent binger & $5.2 \%(n=20)$ & $2.7 \%(n=3)$ \\
\hline \multicolumn{3}{|l|}{ Living situation } \\
\hline On-campus (in residence) & $17 \%(n=66)$ & $14.5 \%(n=16)$ \\
\hline Off-campus (with family) & $29.4 \%(n=114)$ & $30.9 \%(n=34)$ \\
\hline Off-campus (without family) & $53.6 \%(n=208)$ & $54.5 \%(n=60)$ \\
\hline \multicolumn{3}{|l|}{ Year of study } \\
\hline 1st year undergraduate & $21.9 \%(n=85)$ & $22.7 \%(n=25)$ \\
\hline 2nd year undergraduate & $22.9 \%(n=89)$ & $19 \%(n=21)$ \\
\hline 3rd year undergraduate & $24.5 \%(n=95)$ & $30 \%(n=33)$ \\
\hline 4th year undergraduate & $16.8 \%(n=65)$ & $18 \%(n=20)$ \\
\hline $5^{\text {th }}$ year undergraduate & $9.3 \%(n=36)$ & $5 \cdot 5 \%(n=6)$ \\
\hline Graduate & $4.6 \%(n=18)$ & $4.5 \%(n=5)$ \\
\hline Type of sport & Time $1(N=388)$ & Time $2(n=110)$ \\
\hline Team sport ${ }^{\mathrm{b}}$ & $71.4 \%(n=277)$ & $65.5 \%(n=72)$ \\
\hline Individual sport ${ }^{\mathrm{c}}$ & $28.6 \%(n=111)$ & $25 \cdot 5 \%(n=38)$ \\
\hline \multicolumn{3}{|l|}{ Year of sport participation } \\
\hline First & $29.4 \%(n=114)$ & $27 \cdot 3 \%(n=30)$ \\
\hline Second & $20.4 \%(n=79)$ & $21.8 \%(n=24)$ \\
\hline Third & $24.7 \%(n=96)$ & $30.9 \%(n=34)$ \\
\hline Fourth & $16 \%(n=62)$ & $12.7 \%(n=14)$ \\
\hline Fifth & $9.5 \%(n=37)$ & $7 \cdot 3 \%(n=8)$ \\
\hline Previous mental illness diagnosis & $12 \%(n=46)$ & $18 \%(n=20)$ \\
\hline
\end{tabular}

${ }^{\text {a }} 37$ individuals did not provide sufficient data to be classified; ${ }^{\mathrm{b}}$ Team sport = basketball, football, volleyball, soccer, rugby, ice hockey, field hockey, curling, baseball; ' Individual sport = athletics, swimming, rowing, badminton, fencing, skiing, squash, wrestling. 


\section{Instruments}

Student-athletes' MHF was assessed using the Adult Mental Health ContinuumShort Form (MHC-SF; Keyes et al., 2008), a 14-item self-report instrument comprising three subscales (emotional well-being [EWB], social well-being [SWB], and psychological well-being [PWB]). EWB items $(n=3)$ measured whether student-athletes felt happy, interested, and satisfied with life. SWB items $(n=5)$ assessed their perceptions of their social contribution, integration, actualization, acceptance, and coherence. Lastly, PWB ( $n$ = 6) items measured student-athletes' self-acceptance, perceptions of mastery, positive relations with others, personal growth, autonomy, and purpose in life. Student-athletes were asked to rate how they had been feeling during the past month using a 6-point Likert scale from never (0) to every day (5). The MHC-SF provides a continuous assessment (level of mental health based on a summation of the three well-being subscale scores), as well as a categorical assessment of mental health (i.e., flourishing, moderate, languishing). Individuals categorized as having flourishing mental health answered "every day during the past month" or "almost every day during the past month" for at least one of the three items measuring EWB, and at least six of the 11 items measuring positive functioning (SWB and PWB). On the other hand, individuals categorized as languishing reported "never during the past month" or "once or twice during the past month" for at least one of the three items of EWB and at least six of the 11 items of positive functioning. Those who were neither flourishing nor languishing were categorized as having moderate mental health (Keyes, 2009a). The MHC-SF has shown excellent internal consistency ( $>.80$ ) and discriminant validity in adolescents (ages 12-18) and adults in the United States, Netherlands, and South Africa (e.g., Keyes, 2005; Lamers, Westerhof, Bohlmeijer, Klooster, \& Keyes, 2011; Westerhof \& Keyes, 2010). The three-factor structure of the long and short forms of the MHC has been confirmed in nationally representative samples of U.S. adults (e.g., Gallagher, Lopez, \& Preacher, 2009) and adolescents (Keyes, 2005, 2009b), and in college students (Robitschek \& Keyes, 2009). The validated French-language version of the MHC-SF used by Statistics Canada (2015) in the Canadian Community Health Survey-Mental Health was available for francophone student-athletes.

Student-athletes also answered an English or French demographic questionnaire at Time 1 to allow us to describe the sample and understand individual differences that may be related to their overall functioning (i.e., gender, alcohol use, living situation, year of study, type of sport, previous mental illness diagnosis). Items were adapted from largescale national studies (e.g., Statistics Canada, 2015) whenever possible. Student-athletes' drinking habits were assessed using three items from the Harvard School of Public Health's College Alcohol Study (Wechsler, Davenport, Dowdall, Moeykens, \& Castillo, 1994). ${ }^{2}$ The measure (a) classifies respondents' alcohol consumption, (b) is a standard measure of risky alcohol use among American college students (Wechsler \& Austin, 1998), and (c) has been used with NCAA athletes as well (Nelson \& Wechsler, 2001). Student-athletes were categorized as either (a) "non-drinkers" (never drank alcohol or had not done so in the last year); (b) "non-binge drinkers" (consumed alcohol in the past year, but did not binge in the past 30 days); (c) "infrequent bingers" (consumed alcohol in the past year, and binged only once or twice over the past 30 days); and (d) "frequent binge drinkers" (consumed alcohol in the past year, and binged three or more times in the past 30 
days). ${ }^{3}$ Binge drinking was deemed particularly important to assess due to its correlation with experiencing negative outcomes as a result of alcohol consumption (e.g., risky sexual behaviour, physical harm) in university students (Wechsler et al., 1994). Moreover, student-athletes have been found to be more likely to engage in binge drinking than their non-athlete peers (Nelson \& Wechsler, 2001). Respondents also indicated (a) if they were living "on campus," "off-campus with family," or "off-campus without family"; (b) their year of study; (c) the varsity sport(s) in which they were competing; and (d) if they had ever been diagnosed with a mental illness (optional).

\section{Procedures}

Student-athletes were invited to partake in the study at Time 1 (November 2015) via an email from their athletic director and/or via the Student-Athlete Mental Health Initiative's (SAMHI) website and social media platforms. They were given a four-week window to complete the online survey. Athletic directors emailed a reminder message after the first two weeks of this time period. Student-athletes were invited to include their institutional email address at the end of the survey if they wanted to receive an invitation to participate at Time 2 (March 2016). Those who provided their email address received an electronic link to repeat the MHC-SF (but not the demographic questionnaire) in March 2016. November and March were specifically chosen to coincide with midterm (November) and final (March) examinations, in recognition of the significant stress academics place on student-athletes (Humphrey et al., 2013). Furthermore, the choice of November and March reflects an effort to capture student-athlete data during an "in-season" period, as the majority of nationally- and regionally-sanctioned sports are in season during at least one of these time points. This decision acknowledges the gruelling training, travel, and competition demands that could further impact student-athletes' stress levels (Kimball \& Freysinger, 2003). The survey took approximately 20-25 minutes to complete at both time points. Ethics approval was obtained from the host institution to conduct this study and from all universities from which student-athletes were recruited through athletic directors

\section{Data Analysis and Results}

All statistical analyses were carried out in SPSS Version 21.0. A missing data analysis test was performed and revealed that only $2.75 \%$ of the data were missing, rendering the influence of these missing data negligible (Tabachnick \& Fidell, 2013). Missing data were treated with multiple imputations using an expectation-maximization method (Tabachnick \& Fidell, 2013). Data did not violate assumptions of univariate (no instances of skewness or kurtosis) or multivariate normality (no Mahalanobis d-squared scores were significant at $p<.001$; Kline, 2010). Internal consistency reliability coefficients were computed for the English and French versions of the Mental Health Continuum-Short Form at Time $1(N=388)$ and Time $2(n=110)$. Alpha coefficients ranged from 0.722 and 0.935 and were deemed acceptable (DeVellis, 2012). See Table 2 for descriptive statistics and internal consistency coefficients grouped by time and questionnaire language. 
Table 2. Descriptive Statistics and Internal Consistency Coefficients

\begin{tabular}{|c|c|c|c|}
\hline \multicolumn{4}{|c|}{ Time $1(N=388)$, Range $=0.722 \leq \alpha \leq 0.935$} \\
\hline MHC-SF scale & $M(S D)$ & Skewness(Error) & Kurtosis(Error) \\
\hline EWB & $11.2(2.6)$ & $-.430(.23)$ & $-.392(.457)$ \\
\hline SWB & $15.6(5.3)$ & $-.369(.23)$ & $-.620(.457)$ \\
\hline PWB & $20.5(6.1)$ & $-.571(.23)$ & $-.297(.457)$ \\
\hline \multicolumn{2}{|c|}{ ENGLISH $(n=363)$} & \multicolumn{2}{|c|}{ FRENCH $(n=25)$} \\
\hline Measure & Internal consistency & Measure & Internal consistency \\
\hline MHC-SF & $\alpha=0.932$ & MHC-SF & $\alpha=0.876$ \\
\hline EWB & $\alpha=0.891$ & EWB & $\alpha=0.935$ \\
\hline SWB & $a=0.863$ & SWB & $\alpha=0.872$ \\
\hline PWB & $\alpha=0.869$ & PWB & $\alpha=0.722$ \\
\hline \multicolumn{4}{|c|}{ Time $2(n=110)^{\mathrm{a}}$, Range $=0.866 \leq \alpha \leq 0.929$} \\
\hline MHC-SF scale & $M(S D)$ & Skewness(Error) & Kurtosis(Error) \\
\hline EWB & $10.9(2.9)$ & $-.415(.23)$ & $-.863(.457)$ \\
\hline SWB & $14.6(5.1)$ & $.165(.23)$ & $-1.08(.457)$ \\
\hline PWB & $19.3(5.9)$ & $-.148(.23)$ & $-.668(.457)$ \\
\hline \multicolumn{2}{|c|}{ Measure } & \multicolumn{2}{|c|}{ Internal consistency } \\
\hline \multicolumn{2}{|c|}{ MHC-SF } & \multicolumn{2}{|c|}{$\alpha=0.929$} \\
\hline \multicolumn{2}{|c|}{ EWB } & \multicolumn{2}{|c|}{$\alpha=0.873$} \\
\hline \multicolumn{2}{|c|}{ SWB } & \multicolumn{2}{|c|}{$\alpha=0.866$} \\
\hline \multicolumn{2}{|c|}{ PWB } & \multicolumn{2}{|c|}{$\alpha=0.884$} \\
\hline
\end{tabular}

Note. $M=$ mean; $S D=$ standard deviation; MHC-SF = Mental Health Continuum-Short Form; $\mathrm{EWB}=$ emotional wellbeing; SWB = social wellbeing; $\mathrm{PWB}=$ psychological wellbeing. ${ }^{a}$ Not split by language because there was only one French language respondent at Time 2 .

Standard cut-off points to classify levels of mental health functioning (MHF) are not specified in the literature. Thus we created cut-offs based on standardized average scores for each dimension of well-being. The sample mean total scores for each dimension of well-being (i.e., emotional [EWB], social [SWB], and psychological [PWB]) were divided by the number of questionnaire items making up each respective dimension (i.e., three, five, six). Standardized scores therefore fell within the range of the MHC-SF's Likert scale (i.e., 0-5), indicating, on average, how often participants experienced each dimension of subjective well-being over the past month. In line with Keyes' (2009a) guidelines for denoting individuals as languishing, flourishing, or moderately mentally healthy, scores 
falling between o and 1.49 (i.e., average response of "never" or "once or twice") placed individuals in the "low" mental health category. Similarly, scores between 1.5 and 3.49 (i.e., average response of "about once a week" or "about 2 or 3 times a week") and 3.5 and 5 (i.e., average response of "almost every day" or "every day") indicated moderate and high MHF, respectively. Based on these cut-offs, at Time 1, student-athletes reported high levels of EWB (3.7), moderate levels of SWB (3.2), and high levels of PWB (3.5). At Time 2, respondents' EWB (3.6) and SWB (3.0) remained high and moderate; however, their average PWB (3.2) was moderate.

A categorical assessment was also performed to determine the prevalence of studentathletes who were languishing, moderately mentally healthy, and flourishing (see Table 3). As described in the instrument section, categories were scored as indicated by Keyes (2009a), based on the frequency with which respondents felt symptoms of well-being in the last month. We expected that a greater proportion of student-athletes would be languishing as opposed to flourishing. Contrary to our hypothesis, results showed that the opposite was true at Time 1 (1.8\% = languishing, $52.7 \%=$ moderately mentally healthy, $45.5 \%=$ flourishing $)$ and Time $2(1.8 \%=$ languishing, 51.8\% = moderately mentally healthy, $44 \cdot 5 \%$ = flourishing).

Table 3. Level and Prevalence of MHF Across Time ${ }^{\mathrm{a}}$

\begin{tabular}{lcc}
\hline & Time 1 & Time 2 \\
\hline Level of MHF & $M(S D)$ & $M(S D)$ \\
EWB & $3.7(0.9)$ & $3.6(1.0)$ \\
SWB & $3.2(1.0)$ & $3.0(1.0)$ \\
PWB & $3.5(1.0)$ & $3.2(1.0)$ \\
Total MHF & $47.3(12.5)$ & $43.9(12.8)$ \\
Prevalence of MHF & Time 1 & Time 2 \\
Languishing & $1.8 \%(n=2)$ & $1.8 \%(n=2)$ \\
Moderately mentally healthy & $52.7 \%(n=58)$ & $51.8 \%(n=59)$ \\
Flourishing & $45.5 \%(n=50)$ & $44.5 \%(n=49)$ \\
\hline
\end{tabular}

Note. $\mathrm{MHF}=$ mental health functioning; $\mathrm{EWB}=$ emotional wellbeing;

SWB = social wellbeing; $\mathrm{PWB}=$ psychological wellbeing; $M=$ mean, $S D=$ standard deviation.

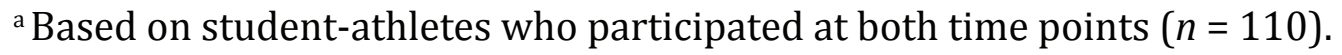

Categorical indices are also provided for student-athletes with and without a previous diagnosis (by a licensed medical professional) of clinical mental illness (e.g., depression, bipolar, eating disorder, obsessive compulsive disorder, etc.; see Table 4). This information was derived from student-athletes' responses to the demographic questionnaire. Cell sizes were not sufficient ( $n>5$; Tabachnick \& Fidell, 2013) to perform cross-tab analyses to examine whether having a previous diagnosis influenced the prevalence of studentathletes who were languishing, moderately mentally healthy, and flourishing. Thus, the cells for languishing and moderately mentally healthy were collapsed and subsequently labeled as "not flourishing." A chi-square analysis was then performed to assess whether having a previous diagnosis influenced the prevalence of athletes who were "flourishing" 
or "not flourishing" at Time 1 and Time 2. The chi-square test results for Time 1 showed a significant association between previous diagnosis of mental illness and whether or not athletes were classified as flourishing, $\mathrm{c}^{2}(1, N=375)=12.11, p<.001$. Based on the odds ratio, athletes were 3.18 times as likely to be classified as flourishing if they had not reported a previous diagnosis than if they reported a previous diagnosis. In contrast to Time 1 , the chi-square test for Time 2 was not significant, $\mathrm{c}^{2}(1, N=110)=2.355, p=.125$.

Table 4. Level and Prevalence of MHF Based on Student-Athletes With and Without a Previous Mental Illness Diagnosis ${ }^{\mathrm{a}}$

\begin{tabular}{lcccc}
\hline & \multicolumn{2}{c}{ Time $1(N=388)$} & \multicolumn{2}{c}{ Time $2(n=110)$} \\
\hline & $\begin{array}{c}\text { Diagnosis } \\
(n=46)\end{array}$ & $\begin{array}{c}\text { No diagnosis } \\
(n=329)\end{array}$ & $\begin{array}{c}\text { Diagnosis } \\
(n=20)\end{array}$ & $\begin{array}{c}\text { No diagnosis } \\
(n=90)\end{array}$ \\
\hline Level of MHF & $M(S D)$ & $M(S D)$ & $M(S D)$ & $M(S D)$ \\
EWB & $3.4(1.1)$ & $3.8(.88)$ & $3.0(0.9)$ & $3.8(1.0)$ \\
SWB & $2.7(1.1)$ & $3.3(.98)$ & $2.5(1.0)$ & $3.0(1.0)$ \\
PWB & $3.0(1.0)$ & $3.5(.91)$ & $3.1(1.0)$ & $3.5(1.0)$ \\
Prevalence of MHF & Diagnosis & No diagnosis & Diagnosis & No diagnosis \\
Languishing & $8.7 \%(n=4)$ & $1.8 \%(n=6)$ & $5 \%(n=1)$ & $1.1 \%(n=1)$ \\
Moderately men- & $63 \%(n=29)$ & $42.6 \%(n=140)$ & $65 \%(n=13)$ & $50.0 \%(n=45)$ \\
$\quad$ tally healthy & & & & \\
Flourishing & $28.3 \%(n=13)$ & $55.6 \%(n=183)$ & $30 \%(n=6)$ & $48.9 \%(n=44)$ \\
\hline
\end{tabular}

Note. $M=$ mean; $S D$ = standard deviation; EWB = emotional wellbeing; SWB = social wellbeing; $\mathrm{PWB}=$ psychological wellbeing; $\mathrm{MHF}=$ mental health functioning.

${ }^{a} n=13$ preferred not to disclose whether they had been previously diagnosed with a mental illness and were excluded from the analysis.

Five separate repeated measures multivariate analyses of variance (MANOVA) were conducted to test whether student-athletes' MHF changed over time (Time 1 to Time 2) depending on their gender (male, female), alcohol use (non-drinker, non-binger, infrequent binger, frequent binger), living situation (on-campus, off-campus with family, offcampus without family), year of study (first year, subsequent years), and type of sport (individual, team). The three dimensions of MHF (i.e., EWB, SWB, PWB) served as the dependent variables measured at both time points. The five MANOVAs were conducted using only the data from athletes who responded at both time points $(n=110)$. Due to the unequal sample size of the independent groups, Pillai's trace was used to assess multivariate significance. To account for the use of multiple MANOVAs, the $p$-value used to determine significance was adjusted to 0.01 (Tabachnick \& Fidell, 2013). Box's M values for each of the MANOVAs were associated with non-significant $p$ values, which suggested that the covariance matrices between groups were equal for the purposes of the MANO- 
VAs (Tabachnick \& Fidell, 2013). Findings indicate that there were no significant main effects of time in any of the MANOVAs. Furthermore, there were no significant interactions between time and any of the independent variables (see Table 5 for summary statistics of main effects of time and independent variables and interaction effects of time and each independent variable).

Table 5. Summary of Main and Interaction Effects of Gender, Alcohol Use, Living Situation, Year of Study, and Type of Sport on MHF for Five Separate RM-MANOVAs

\begin{tabular}{|c|c|c|c|c|c|c|}
\hline Main effects & $V$ & $F$ & $D F$ & $D F$ Error & $p$ & $\eta_{\mathrm{p}}^{2}$ \\
\hline Time (gender) ${ }^{\mathrm{a}}$ & .045 & 1.657 & 3 & 106 & .181 & .045 \\
\hline Gender & .010 & .340 & 3 & 106 & .796 & .010 \\
\hline Time (alcohol use) & .055 & 1.985 & 3 & 103 & .121 & .055 \\
\hline Alcohol use & .047 & .850 & 6 & 212 & .533 & .023 \\
\hline Time (living situation) & .061 & 2.276 & 3 & 105 & .084 & .061 \\
\hline Living situation & .099 & .897 & 12 & 315 & .55 & .033 \\
\hline Time (year of study) & .063 & 2.391 & 3 & 106 & .391 & .028 \\
\hline Year of study & .022 & .813 & 3 & 106 & .489 & .022 \\
\hline Time (type of sport) & .05 & 1.853 & 3 & 106 & .391 & .028 \\
\hline Type of sport & .017 & .607 & 3 & 106 & .612 & .017 \\
\hline Interaction effects & $V$ & $F$ & $D F$ & $D F$ Error & $p$ & $\eta_{\mathrm{p}}^{2}$ \\
\hline Time ${ }^{*}$ Gender & .015 & .541 & 3 & 106 & .656 & .015 \\
\hline Time ${ }^{*}$ alcohol use & .107 & .974 & 12 & 315 & .474 & .036 \\
\hline Time * living situation & .029 & .517 & 6 & 212 & .795 & .014 \\
\hline Time * year of study & .028 & 1.01 & 3 & 106 & .391 & .028 \\
\hline Time * type of sport & .066 & 2.497 & 3 & 106 & .064 & .066 \\
\hline
\end{tabular}

Note. $V=$ Pillai's trace; $F=$ F-ratio; $D F=$ degrees of freedom; $p=$ significance value;

$\eta_{\mathrm{p}}{ }^{2}=$ partial eta square; $\mathrm{MHF}=$ mental health functioning.

${ }^{a}$ Main effects of time, independent variable denoted in brackets.

\section{Discussion}

The objective of this study was to provide a baseline understanding of the mental health functioning (MHF) of student-athletes competing in the Canadian USports system. We hypothesized that their MHF would be low to moderate, vary based on gender, alcohol use, living situation, year of study, and type of sport, and decline over the course of the year. Contrary to our hypotheses, the student-athletes in this sample generally experienced moderate to high levels of MHF. Relative to MHF levels reported in other studies with university students (e.g., low to moderate levels in a study by Durand-Bush, McNeil, 
Harding, \& Dobransky, 2015), the MHF reported by the student-athletes in this sample appears to be elevated. These results are confounding given the mental health concerns for student-athletes raised by other researchers (e.g., Humphrey et al., 2013; Neal et al., 2013). Results from our categorical assessment were also contrary to our hypotheses. Specifically, a greater portion of athletes appeared to be flourishing than languishing at both time points. Additionally, in comparison to Peter and colleagues' (2011) study with Canadian university students, in which $24 \%$ of the sample was flourishing, there was a higher prevalence of student-athletes flourishing in the current study (46\%). We expected to see a greater proportion of student-athletes languishing as opposed to flourishing due to the multiple risk factors that can be associated with being both a university student and varsity athlete (e.g., multiple sources of stress, risk of burnout, injury, often conflicting roles of student and athlete).

At first glance, these results may seem encouraging, yet they are but a first look into student-athletes' MHF and perhaps do not tell the whole story. For instance, Eklund, Dowdy, Jones, and Furlong (2011) found that American college students with similar overall mean levels of MHF to the athletes in our study were classified as being at-risk (i.e., demonstrating low life satisfaction but also low clinical symptoms of depression; $M$ $=48.4$ ) or ambivalent (i.e., demonstrating high life satisfaction but moderate to high levels of clinical symptoms; $M=46.2$ ). Similarly, $1.7 \%$ of the "flourishing" students in Peter and colleagues' (2011) inquiry were found to be experiencing symptoms of well-being and depression simultaneously. Durand-Bush, McNeil, Harding, and Dobransky (2015), who studied Canadian undergraduate students, reported similar findings in that participants experienced moderate levels of stress and low levels of MHF concurrent with moderately high psychological well-being. Together, these studies suggest that high scores on MHF do not guarantee the absence of mental health challenges.

Results from our demographic questionnaire showed that $18 \%(n=20)$ of the 110 student-athletes who participated at both time points reported a previous diagnosis of mental illness. These individuals maintained moderate EWB, SWB, and PWB across time, despite this self-reported diagnosis, supporting Keyes' (2002) dual-continua model and confirming the findings of other studies (e.g., Durand-Bush et al., 2015; Peter et al., 2011) showing that mental illness does not automatically imply low levels of well-being. However, a chi-square test revealed that those who did not report a previous diagnosis of mental illness were 3.18 times more likely to be flourishing at Time 1 , suggesting that a diagnosis of a mental illness may decrease the likelihood of flourishing in student-athletes. Further research is warranted to discover moderating factors in the relationship between student-athletes' mental health and mental illness. Measuring symptoms of mental illness, in conjunction with mental health scales such as the MHC-SF (Keyes, 2002), is recommended to shed more light on the subject in the future.

The moderate and high levels of MHF reported by the student-athletes in this study could possibly be attributed to the benefits of sport. Several researchers have demonstrated the positive impact of sport on the lives of student-athletes (e.g., Watt et al., 2001). As Kimball and Freysinger (2003) have suggested, even though athletes face stressful demands, sporting activities may act as a buffer to stress when they facilitate self-determination, self-control, and competence. It is thus possible that the student-athletes in the current study were highly self-regulated individuals capable of balancing their sport and academic workload. Nevertheless, one must be mindful that university students have been 
shown to experience high levels of stress (e.g., ACHA, 2009), and student-athletes may be especially vulnerable to ill-being due to the excessive and often conflicting stressors imposed upon them (Humphrey et al., 2013). One must also consider that student-athletes may be over-reporting high functionality and under-reporting ill-being symptoms due to a prevailing mental illness stigma and the expectation in sport to demonstrate mental toughness and push through injury and illness (Steiner, Denny, \& Stemmle, 2010). Such attitudes and norms have fostered an underutilization of counseling services by NCAA student-athletes, and are a barrier to help-seeking within this population (Brown, 2014). Lopez and Levy (2013) identified that the fear of stigma for seeking mental health services, the fear of teammates finding out that they are in treatment, and the fear of being considered weak prevent student-athletes from getting assistance. Similarly, Delenardo and Terrion (2014) found that Canadian university football players unanimously reported that mental illness is perceived as a reflection of weak character. The players also stated that showing compassion and understanding for a teammate with a mental illness puts athletes at risk of being viewed by peers as "weak-minded" as well. If this is indeed the case, more work must be done to normalize the conversation and treatment surrounding mental health struggles in student-athletes. To aid in this endeavor, post-secondary institutions may consider adding mental health screening as part of their mandatory pre-season examination of student-athletes (Sudano, Collins, \& Miles, 2017). This will not only generate additional data on the mental health of Canadian student-athletes but will, more importantly, present an opportunity to assess baseline levels and adopt preventative measures with athletes flagged as "at risk" of experiencing compromised mental health.

Our other hypothesis was also unsupported, that is, there were no significant differences in student-athletes' MHF from Time 1 to Time 2 and based on gender, alcohol use, living situation, year of program, or type of sport. The multiple analyses performed indicate that, collectively, the student-athletes in this study experienced fairly stable MHF over the academic year and athletic season, and their MHF did not vary over the season based on the aforementioned individual differences. This was surprising, considering that other researchers have found individual differences to predict significant disparities in well-being (e.g., Adlaf et al., 2005; Dubuc-Charbonneau et al., 2014; Nelson \& Wechsler, 2001; Nixdorf et al., 2016; Park et al., 2012). At the same time, conceptions of mental health are widely contested (Uphill et al., 2016), and measures of mental health and illness vary to a large degree; thus, these incongruities within the research and health communities may explain some of the discrepancies among results.

Despite the strengths of this study, there are limitations worth discussing. Only 388 of the 1124 student-athletes who accessed the survey at Time 1 provided sufficient information to be included in the study (not a large enough sample to be considered representative of the approximate 12,000 student-athletes who compete in USports athletics each year). Furthermore, high attrition from Time 1 to Time 2 (72\%) diminished the statistical power of repeated-measures MANOVA tests. Attrition may be attributed to the busy life of studentathletes; completing the survey at Time 1 and 2 may have been perceived as an additional demand that some student-athletes could not fulfill. Additionally, despite meeting ethical requirements of confidentiality and anonymity, the use of self-report questionnaires may have allowed student-athletes to over-report their level of MHF for fear of being stigmatized. Furthermore, despite the acceptable internal consistency coefficients of the MHC$\mathrm{SF}$, it is possible that the items did not fully capture the functioning of student-athletes, 
given that their demands and priorities are different than those of non-athlete university populations. It is recommended that a confirmatory factor analysis be performed on the MHC-SF to assess its relevancy within a student-athlete population in the future. Lastly, we recognize the limitations of assessing mental illness through a singular self-report item (i.e., "Have you been previously diagnosed with a mental illness by a health care practitioner?"). Future studies can improve upon our approach by including an objective measure of mental illness, pathology, or distress. Given that this is the first study to examine the MHF of Canadian student-athletes, more studies are warranted so that trends and mental health profiles can be derived to inform Canadian policy and practice.

\section{Conclusion and Practical Implications}

This study showed that the MHF of a sample of USports student-athletes was moderate to high across the 2015-2016 athletic and academic year. Although $18 \%$ of respondents reported being previously diagnosed with a mental illness, these individuals maintained moderate MHF across time. Furthermore, more student-athletes were flourishing than languishing at both time points. That being said, those without a previous diagnosis of mental illness were 3.18 times more likely to be flourishing at Time 1. Contrary to our hypotheses, MHF did not vary across time and based on individual differences such as gender, alcohol use, living situation, year of study, and type of sport. However, the small sample size may have limited our ability to detect significant differences.

The overall non-significant results justify the exploration of other factors, beyond demographics, that could be influencing the MHF of USports student-athletes. Given that sport can buffer stress and facilitate self-determination and self-control (Kimball \& Freysinger, 2003), it would be interesting to examine the relationship between stress, self-regulation capacity, and MHF in this population. Self-regulation may be of particular importance for student-athletes who have been previously diagnosed with a mental illness, given that our results indicate they may less likely to be flourishing.

From a practical standpoint, the results of this study provide a preliminary baseline understanding of Canadian university athletes' MHF. The majority of student-athletes, including those who reported a previous mental illness diagnosis, were moderately mentally healthy and could be considered "ambivalent" or "at risk" of experiencing mental health challenges (Eklund et al., 2011). Yet this potentially vulnerable group has lacked attention in research, as the absence of clinical symptoms of mental illness has remained the dominant focus of well-being research and programming. With calls for a shift toward mental health prevention and promotion, the moderately mentally healthy deserve closer attention because although they are not in distress, they are not optimally functioning, either. Programs and activities focused on promoting and maintaining positive mental health and reducing mental illness stigma within the athletics community will be important first steps in ensuring the future well-being of student-athletes.

\section{Notes}

1. A score of 16 or greater on the CES-D identifies individuals at risk of clinical depression (Lewinsohn, Seeley, Roberts, \& Allen, 1997).

2. The three items used to classify drinkers as described in Wechsler et al. (1994) are as follows: (1) gender; (2) passage of time since last drink ("never," "not in the past year," 
"within the year but more than 30 days ago," "within 30 days but more than 1 week ago," "within 1 week"); and (3) frequency of meeting harmful drinking threshold (e.g., "How many times over the last two weeks have you had four (women)/five (men) or more drinks in a row?").

3. A "drink" was defined as 12 ounces of beer (one can), four ounces of wine (one glass), a 12-ounce wine cooler, or one shot of liquor (Nelson \& Wechsler, 2001).

\section{References}

Adlaf, E., Demers, A., \& Gilksman, L. (2005). Canadian campus survey: Centre for Addiction and Mental Health. Toronto, ON: Centre for Addiction and Mental Health.

American College Health Association [ACHA]. (2009). National college health assessment: Ontario reference group executive summary. Linthicum, MD: Author.

American College Health Association [ACHA]. (2013). National College Health Assessment-II: Canadian reference group executive summary spring 2013. Hanover, MD: Author.

Aries, E., McCarthy, D., Salovey, P., \& Banaji, M. (2004). A comparison of athletes and non-athletes at highly selective colleges: Academic performance and personal development. Research in Higher Education, 45(6), 577-602. doi:10.1023/ B:RIHE.ooooo40264.76846.e9

Bär, K. J., \& Markser, V. Z. (2013). Sport specificity of mental disorders: The issue of sport psychiatry. European Archives of Psychiatry and Clinical Neuroscience, 263(2), 205-210. doi:10.2165/s00406-013-0458-4

Beauchemin, J. (2014). College student-athlete wellness: An integrative outreach model. College Student Journal, 48(2), 268-280.

Brewer, B. W., \& Petrie, T. A. (2002). Psychopathology in sport and exercise. In J. L. Van Raalte \& B. L. Brewer (Eds.), Exploring sport and exercise psychology (pp. 307323). Washington, DC: American Psychological Association.

Brown, G. T. (2014). Mind, body and sport. Indianapolis, IN: National Collegiate Athletic Association.

Clapham, L., Jahchan, R., Medves, J., Tierney, A., \& Walker, D. (2012). Student mental health and wellness: Framework and recommendations for a comprehensive strategy. Kingston, ON: Queen's University Principal's Commission on Mental Health.

Delenardo, S., \& Terrion, J. (2014). Suck it up: Opinions and attitudes about mental illness stigma and help-seeking behaviour of male varsity football players. Canadian Journal of Community Mental Health, 33(3), 43-56.

DeVellis, R. (2012). Scale development: Theory and applications. Newbury Park, CA: Sage Publications.

Dubuc-Charbonneau, N. M., Durand-Bush, N., \& Forneris, T. (2014). Student-athlete burnout: Exploring levels and trends at two Canadian universities. Canadian Journal of Higher Education, 44(2), 135-151. 
Durand-Bush, N., McNeil, K., Harding, M., \& Dobransky, J. (2015). Investigating stress, psychological well-being, mental health functioning, and self-regulation capacity among university undergraduage students: Is this population optimally functioning? Canadian Journal of Counselling and Psychotherapy, 49(3), 253-274.

Dyson, R., \& Renk, K. (2006). Freshmen adaptation to university life: Depressive symptoms, stress and coping. Journal of Clinical Psychology, 62(10), 1231-1244. doi:10.1002/jclp.20295

Eklund, K., Dowdy, E., Jones, C., \& Furlong, M. (2011). Applicability of the dual-factor model of mental health for college students. Journal of College Student Psychotherapy, 25(1), 79-92. doi:10.1080/87568225.2011.532677

Gallagher, M. W., Lopez, S. J., \&Preacher, K. J.(2009). Thehierarchical structure of wellbeing. Journal of Personality, 77(4), 1025-1049. doi:10.1111/j.1467-6494.2009.00573.x

Gratz, K., Conrad, S. D., \& Roemer, L. (2002). Risk factors for deliberate selfharm among college students. American Journal of Orthopsychiatry, 72(1), 128-140. doi:10.1037/0002-9432.72.1.128

Humphrey, J., Bowden, W., \& Yow, D. (2013). Stress in college athletics. New York, NY: Haworth Press, Inc.

Keyes, C. L. M. (2002). The mental health continuum: From languishing to flourishing in life. Journal of Health and Social Behavior, 43(2), 207-222. Retrieved from http:// www.jstor.org/stable/3090197

Keyes, C. L. M. (2003). Complete mental health: An agenda for the 21st century. In C. L. M. Keyes (Ed.), Flourishing: Positive psychology and the life well-lived (pp. 293-312). Washington, DC: American Psychological Association.

Keyes, C. L. M. (2005). Mental illness and/or mental health? Investigating axioms of the complete state of mental health. Journal of Consulting and Clinical Psychology, 73(3), 539-548. doi:10.1037/0022-006X.73.3.539

Keyes, C. L. M. (2007). Promoting and protecting mental health as flourishing: A complementary strategy for improving national mental health. American Psychologist, 62(2), 95-108. doi:10.1037/0003-066X.62.2.95

Keyes, C. L. M. (2009a). Brief description of the mental health continuum short form (MHC-SF). Atlanta: (n.p.). Retrieved from http://www.sociology.emory.edu/ckeyes/

Keyes, C. L. M. (2009b). The nature and importance of mental health in youth. In R. Gilman, M. Furlong, \& E. S. Huebner (Eds.), Promoting wellness in children and youth: A handbook of positive psychology in the schools (pp. 9-23). New York, NY: Routledge.

Keyes, C. L. M., Wissing, M., Potgieter, J. P., Temane, M., Kruger, A., \& van Rooy, S. (2008). Evaluation of the mental health continuum-short form (MHC-SF) in Setswanaspeaking South Africans. Clinical Psychology \& Psychotherapy, 15(3), 181-192. doi:10.1002/cpp.572

Kimball, A., \& Freysinger, V. (2003). Leisure, stress, and coping: The sport participation of collegiate student-athletes. Leisure Sciences: An Interdisciplinary Journal, 25(2-3), 115-141. doi:10.1080/01490400306569 
Kline, R. (2010). Principles and practice of structural equation modeling (3rd ed.). New York, NY: The Guildford Press.

Lamers, S., Westerhof, G., Bohlmeijer, E., Klooster, P., \& Keyes, C. L. M. (2011). Evaluating the psychometric properties of the Mental Health Continuum-Short Form (MHC-SF). Journal of Clinical Psychology, 67(1), 99-110.

Lewinsohn, P. M., Seeley, J. R., Roberts, R. E., \& Allen, N. B. (1997). Center for Epidemiological Studies-Depression Scale (CES-D) as a screening instrument for depression among community-residing older adults. Psychology and Aging, 12(2), 277287.

Lopez, R., \& Levy, J. (2013). Student athletes' perceived barriers to and preferences for seeking counseling. Journal of College Counseling, 16(1), 19-31. doi:10.1002/j.21611882.2013.00024.x

Mikolajczyk, R., Maxwell, A., Naydenova, V., Meier, S., \& Ansari, W. (2008). Depressive symptoms and perceived burdens related to being a student: Survey in three European countries. Clinical Practice and Epidemiology in Mental Health, 4(19), 1-9. doi:10.1186/1745-0179-4-19

Miller, P. S., \& Kerr, G. (2002). The athletic, academic and social experiences of intercollegiate student-athletes. Journal of Sport Behaviour, 25(4), 346-367.

Misra, R., \& McKean, M. (2000). College students' academic stress and its relation to their anxiety, time-management and leisure satisfaction. American Journal of Health Studies, 16(1), 41-51.

National Collegiate Athletic Association [NCAA]. (2007). Managing student-athletes' mental health issues. Indianapolis, IN: Author.

Neal, T., Diamond, A. B., Goldman, S., Liedtka, K. D., Mathis, K., Morse, E., Putukian, M.., ... Welzant, V. (2013). Interassociation recommendations in developing a plan for recognition and referral of student-athletes with psychological concerns at the collegiate level: A consensus statement. Journal of Athletic Training, 48(5), 716-720. doi:10.4085/1062-6050-48.4.13

Nelson, T. F., \& Wechsler, H. (2001). Alcohol and college athletes. Medicine and Science in Sports and Exercise, 33(1), 43-47.

Nixdorf, I., Frank, R., \& Beckmann, J. (2016). Comparison of athletes' proneness to depressive symptoms in individual and team sports: Research on psychological mediators in junior elite athletes. Frontiers in Psychology, 7, 893-900. doi:10.3389/ fpsyg.2016.00893

Park, C., Edmondson, D., \& Lee, J. (2012). Development of self-regulation abilities as predictors of psychological adjustment across the first year of college. Journal of Adult Development, 19(1), 40-49. doi:10.1007/s10804-011-9133-z

Peter, T., Roberts, L., \& Dengate, J. (2011). Flourishing in life: An empirical test of the dual continua model of mental health and mental illness among Canadian university students. International Journal of Mental Health Promotion, 13(1), 13-22. doi:10.1080 /14623730.2011.9715646 
Petrillo, G., Capone, V., Caso, D., \& Keyes, C. L. M. (2015). The Mental Health Continuum-Short Form (MHC-SF) as a measure of well-being in the Italian context. Social Indicators Research, 121(1), 291-312.

Pritchard, M., Wilson, G., \& Yamnitz, B. (2008). What predicts adjustment among college students? A longitudinal panel study. Journal of American College Health, 56(1), 15-21.

Renshaw, T., \& Cohen, A. (2014). Life satisfaction as a distinguishing indicator of college student functioning: Further validation of the two-continua model of mental health. Social Indicators Research, 117(7), 319-334. doi:10.1007/s11205-013-0342-7

Robitschek, C., \& Keyes, C. L. M. (2009). The structure of Keyes' model of mental health and the role of personal growth initiative as a parsimonious predictor. Journal of Counseling Psychology, 56(2), 321-329. doi:10.1037/a0013954

Sasaki, M., \& Yumasaki, K. (2007). Stress coping and the adjustment process among university freshmen. Counseling Psychology Quarterly, 20(1), 51-67. doi:10.1080/09515070701219943

Statistics Canada. (2015). Canadian community health survey-Mental Health. Ottawa, ON: Author. Retrieved from http://www23.statcan.gc.ca/imdb/p3Instr.pl?Fun ction $=$ assembleInstr\&a $=1 \& \& l a n g=e n \& I t e m \_I d=238890$

Steiner, H., Denny, K., \& Stemmle, P. (2010). Adaptive styles in elite collegiate athletes: The role of activation and self-regulation. Personality and Mental Health, 4(3), 163-171. doi:10.1002/pmh.120

Sudano, L. E., Collins, G., \& Miles, C. M. (2017). Reducing barriers to mental health care for student-athletes: An integrated care model. Families, Systems, and Health, 35(1), 77-84.

Suldo, S., \& Shaffer, E. J. (2008). Looking beyond psychopathology: The dual-factor model of mental health in youth. School Psychology Review, 37(1), 52-68.

Tabachnick, B., \& Fidell, L. (2013). Using multivariate statistics. Boston, MA: Allyn and Bacon.

Uphill, M., Sly, D., \& Swain, J. (2016). From mental health to mental wealth in athletes: Looking back and moving forward. Frontiers in Psychology, 7, 935-941. doi:10.3389/ fpsyg.2016.00935

Verger, P., Combes, J.-B., Kovess-Masfety, V., Choquet, M., Guagliardo, V., Rouillon, F., \& Peretti-Wattel, P. (2009). Psychological distress in first year university students: Socioeconomic and academic stressors, mastery and social support in young men and women. Social Psychiatry and Psychiatric Epidemiology, 44(8), 643-650. doi:10.1007/ s00127-008-0486-y

Watson, J. C., \& Kissinger, D. B. (2007). Athletic participation and wellness: Implications for counseling college student-athletes. Journal of College Counseling, 1O(12), 153-162. doi:10.1002/j.2161-1882.2007.tboo015.x

Watt, S., Moore, J., \& Howard-Hamilton, M. (2001). Who are student-athletes? New Directions for Student Services, 2001(93), 7-18. 
Wechsler, H., \& Austin, S. B. (1998). Binge drinking: The five/four measure. Journal of Studies on Alcohol, 59(1), 122-124.

Wechsler, H., Davenport, A., Dowdall, G., Moeykens, B., \& Castillo, S. (1994). Health and behavioral consequences of binge drinking in college: A national survey of students at 140 campuses. Journal of the American Medical Association, 272(21), 1672-1677. doi:10.1001/jama.1994.03520210056032

Westerhof, G. J., \& Keyes, C. L. M. (2010). Mental illness and mental health: The two continua model across the lifespan. Journal of Adult Development, 17(2), 110-119. doi:10.1007/s10804-009-9082-y

Wilson, G., \& Pritchard, M. (2005). Comparing sources of stress in college studentathletes and non-athletes. Athletic Insight, 7(1), 1-8.

Yang, J., Peek-Asa, C., Corlette, J. D., Cheng, G., Foster, D., \& Albright, J. (2007). Prevalence of and risk factors associated with symptoms of depression in competitive collegiate student athletes. Clinical Journal of Sport Medicine, 17(6), 481-487. doi:10.1097/JSM.obo13e31815aed6b

\section{Contact Information}

Krista J. Van Slingerland

School of Human Kinetics

University of Ottawa

krista.vanslingerland@uottawa.ca

Krista Van Slingerland is a PhD candidate in the School of Human Kinetics at the University of Ottawa, where she also completed a master's degree. As the co-founder of a charity called the Student-Athlete Mental Health Initiative (SAMHI), and a former athlete who struggled with mental illness, she continues to lend her efforts to the advancement of the field of mental health in Canada, especially for athletes. With her doctoral project, supervised by Dr. Natalie Durand-Bush, Krista aims to design, implement, and evaluate a Canadian Centre for Mental Health and Sport (CCMHS) to meet the mental health needs of competitive and high-performance athletes and coaches.

Dr. Natalie Durand-Bush is a full professor in the School of Human Kinetics at the University of Ottawa in Canada, and an adjunct professor in the Norwegian School of Sport Sciences in Norway. Her research and professional interests include the development of mental skills and self-regulation interventions to help athletes and coaches achieve not only performance excellence but also mental health and well-being. She co-founded and chaired the Canadian Sport Psychology Association and served as the Vice-President of the International Society of Sport Psychology. She currently is a member of the Executive Board of the Association for Applied Sport Psychology.

Scott Rathwell is an Assistant professor at the University of Lethbridge in the Department of Kinesiology and Physical Education. His research interests revolve around the personal and psychosocial development of university athletes. He also conducts research on the psychosocial factors related to lifelong sport and the mechanisms through which masters athletes are able to maintain their elite performance. 